\title{
FAKTOR-FAKTOR YANG MEMPENGARUHI ORANG TUA DALAM MENCEGAH CEDERA PADA ANAK USIA TODDLER DI PAUD TUNAS BANGSA
}

\author{
FACTORS AFFECTING PARENTS TO PREVENT INJURY IN TODDLER AGES AT \\ PAUD TUNAS BANGSA
}

\author{
Feri Kameliawati ${ }^{1}$, Riska Hediya Putri ${ }^{2}$, Surmiasih ${ }^{3}$ \\ ${ }^{1,2,3}$ Universitas Aisyah Pringsewu \\ e-mail: kameliawatiferi@gmail.com
}

\begin{abstract}
ABSTRAK
Semua orang tua menyebutkan bahwa anak mereka pernah mengalami cedera. Data WHO cedera mengakibatkan 5,8 juta kematian di seluruh dunia. Cedera di Indonesia di dominasi oleh luka lecet/memar sebesar 70,9\%, cedera di provinsi Lampung yang terjadi pada anak meliputi 76,3\% lecet/memar dan untuk Kabupaten Pesawaran sebesar 19\%. Cedera tidak terjadi apabila orang tua memiliki pengetahuan tentang tumbuh-kembang anak usia prasekolah dan sikap yang tanggap jika anak mengalami cedera dan tindakan pencegahan berupa pengawasan dapat dilakukan oleh orang tua, karena dalam beraktivitas anak tidak memperhatikan bahaya yang mungkin akan terjadi. Tujuan penelitian ini adalah untuk mengetahui Faktorfaktor yang mempengaruhi orang tua dalam mencegah cedera pada anak usia toddler di PAUD Tunas Bangsa tahun 2018. Jenis penelitian ini adalah kuantitatif. Penelitian ini mengunakan metode survei dengan pendekatan cross sectional. Penelitian ini telah dilaksanakan di PAUD Tunas Bangsa Negeri Sakti. Adapun waktu pelaksanaannya pada tanggal 5 - 26 Maret 2018. Jumlah populasi adalah orang tua yang memiliki anak usia toddler. Adapun jumlahnya yaitu 41 orang. Sampel sejumlah 41 orang. Teknik pengambilan sampel dalam penelitian ini menggunakan total sampling. Hasil analisis menunjukan faktor yang paling berpengaruh terhadap pencegahan cedera adalah faktor pengetahuan dengan Pvalue $<0,001 \quad(<0.05)$ dengan odds Ratio sebesar 0.011 (0.001- 0.130). Diharapkan hasil penelitian ini dapat memberikan pengetahuan tentang mencegah cedera pada anak. Dan menjadikan sikap orang tua lebih tanggap melakukan pertolongan pada anak yang cedera kemudian lebih berhati-hati dalam mendampingi tumbuh kembang anak karena rasa penasaran anak yang tinggi dapat mengakibatkan adanya cedera pada anak.
\end{abstract}

Kata kunci: Pengetahuan, sikap, pengawasan, cedera pada anak

\begin{abstract}
The parent's mentioned that their child's been injured. WHO riset it's injury resulting 5,8 million deaths around the world. The injury in Indonesia is dominated by the gall / bruises for 70,9\%, injury in the province of Lampung that occur in kids include 76,3\% blisters / bruises and for the Pesawaran by 19\%. Injury not the case when parents have the knowledge of the growing expandable childhood preschool and attitude response if the child's injury and precautions the form of supervision can be done by parents, as in the move children not pay attention to the danger that may occur. Purpose of this research is to determine the factors that affect the parents in prevent injury in children age toddler in PAUD Tunas Bangsa year 2018. This research is quantitative. This study using the method of the survey with cross sectional approach. This study was at PAUD Tunas Bangsa Negeri Sakti. The time implementation on 5-26 March 2018. The population is parents have toddler as 41 people. Sample of as 41 people. Sampling technique in this study using a total of sampling. Analysis shows the factors that most influential to injury prevention is a factor of knowledge with p-value $<0,001(<0.05)$ with the odds ratio of 0.011 (0.001-0.130). Expected results of this study can provide knowledge of prevent injury in children. And make the attitude of parents more responsive to aid in children injured then more careful in the accompanying the child development because of curiosity child high may result in the injury in children.
\end{abstract}

Key word: Knowledge, attitude, supervision, injury to children 


\section{PENDAHULUAN}

Menurut World Health Organization (WHO) cedera mengakibatkan 5,8 juta kematian di seluruh dunia, dan lebih dari 3 juta kematian diantaranya terjadi di negara-negara berkembang. Cedera mengakibatkan 7\% kematian diseluruh dunia dan angka ini masih terus bertambah. World Health Organization (WHO) menyebutkan bahwa tidak kurang dari 875.000 anak dibawah 18 tahun di seluruh dunia meninggal per tahun karena cedera, baik cedera yang disengaja maupun yang tidak disengaja. Tahun 2000 dilaporkan bahwa cedera yang disengaja dan tidak disengaja menyebabkan $42 \%$ kematian anak usia 1-4 tahun di Amerika Serikat. Keseluruhan rata-rata cedera pada anak usia 0-3 tahun per tahunnya yaitu sebanyak 371/100.000 anak ${ }^{1}$.

Proporsi jenis cedera di Indonesia di dominasi oleh luka lecet/memar sebesar 70,9\%, terbanyak terdapat di banten $(76,2 \%)$ dan yang terendah di papua yaitu 59,4\%. Jenis cedera terbanyak kedua adalah terkilir, rata-rata di Indonesia 27,5\%. Ditemukan terkilir terbanyak di temukan di Kalimantan selatan sebesar $39,3 \%$, luka luka robek menduduki urutan ketiga jenis cedera terbanyak, jenis luka ini tertinggi ditemukan di papua sekitar $48,5 \%$ jauh di atas Indonesia yaitu $23,2 \%$ dan terendah di Yogyakarta (14,6\%). Jenis jenis cedera lainya proporsinya kecil, patah tulang $5,8 \%$, angota tubuh terputus, cedera mata dan gagar otak masing-masing proporsinya di Indonesia $0,3 \%$, $0,6 \%$ dan $0,4 \%{ }^{2}$. Proporsi jenis cedera di provinsi Lampung yang terjadi pada anak meliputi 76,3\% lecet/memar, 19,7\% luka robek, $4,9 \%$ patah tulang, $36,2 \%$ terkilir, $0,1 \%$ anggota tubuh terputus, $0,6 \%$ cedera mata, $0,3 \%$ gagar otak, $0,7 \%$ lainya. Adapun urutan proporsi terbanyak untuk tempat terjadinya cedera yaitu di jalan raya $(42,8 \%)$, lingkungan rumah $(36,5 \%)$, area pertanian $(6,9 \%)$ dan sekolah $(5,4 \%)^{2}$. Kejadian cedera pada anak berdasarkan kabupaten di provinsi lampung meliputi:
Kabupaten Lampung barat 11\%, Tanggamus 13\%, Lampung Selatan 17\%, Lampung Timur $21 \%$, Kabupaten Lampung Tengah 18\%, Lampung Utara $13 \%$, Way kanan 14\%, Tulang Bawang 15\%, Kabupaten Pesawaran 19\%, Kabupaten Pringsewu 17\%, Mesuji 17\%, Tulang Bawang Barat 12\%, Pesisir Barat 16\%, Bandar Lampung 28\%, dan Metro $13 \%{ }^{3}$.

Semua orang tua menyebutkan bahwa anak mereka pernah mengalami cedera. Upaya yang dilakukan orang tua dalam melakukan penanganan cedera pada anak adalah dengan melihat terlebih dahulu keadaan cederanya. Jika cedera ringan orang tua hanya membiarkan saja atau dengan melakukan penggobatan sendiri di rumah baik dengan cara tradisional ataupun dengan obat yang tersedia di kotak obat. Jika cedera sudah berat maka dilarikan ke fasiltas pelayanan kesehatan untuk mendapatkan pertolongan segera ${ }^{4}$.

Berdasarkan penelitian menyebutkan bahwa faktor lingkungan rumah tempat tinggal anak 43,2\% merupakan faktor yang paling berperan dalam kejadian cedera pada anak-anak dan disusul oleh faktor pengawasaan orangtua yang masih rendah yaitu $32,6 \%$ serta faktor rumah yang tidak cukup luas yaitu 24,2\% sehingga anak harus belajar/ bermain diluar rumah dapat mengurangi kesempatan bagi orang tua untuk melakukan pengawasan terhadap anak $^{4}$.

Studi pendahuluan yang dilakukan di PAUD Tunas Bangsa, PAUD Bina Sanjaya, PAUD Aisyiyah, dan PAUD Mimbaul Ulum. Di PAUD Tunas Bangsa, hasilnya 6 (60\%) orang tua belum tahu benar tentang bahaya cedera dan $4(40 \%)$ orang tua mengetahui bahaya cedera yang mengancam anaknya. Peneliti akan melakukan penelitian di PAUD Tunas Bangsa dengan alasan ada kejadian cedera pada anak akibat jatuh dan kecelakaan, karena letak PAUD yang dekat dengan jalan raya. Pada tahun 2016 tercatat 3 anak mengalami kecelakaan lalu lintas dengan insiden terserempet kendaraan bermotor, 
kemudian peranan guru saat kejadian tersebut dalam menangai cedera dengan cara melarikan ke puskesmas terdekat karena luka terlalu parah. Berdasarkan latar belakang diatas, penulis tertarik untuk meneliti tentang "Faktor-faktor yang mempengaruhi orang tua dalam mencegah cedera pada anak usia toddler di PAUD Tunas Bangsa"

\section{METODE}

Jenis penelitian ini adalah kuantitatif, penelitian kuantitatif adalah metode yang digunakan untuk menyelidiki objek yang dapat diukur dengan angka-angka, sehingga gejalagejala yang diteliti dapat diteliti/diukur dengan menggunakan skala-skala, indeks-indeks atau tabel- tabel yang kesemuanya lebih banyak menggunakan ilmu pasti ${ }^{5}$.

Penelitian ini telah dilaksanakan di PAUD Tunas Bangsa Negeri Sakti. Adapun waktu pelaksanaannya pada tanggal 5 - 26 Maret 2018. Penelitian ini menggunakan desain penelitian analitik, yaitu penelitian yang menyangkut pengujian hipotesis, yang mengandung uraian- uraian tetapi fokusnya terletak pada analisis hubungan antara variabel ${ }^{5}$. Pendekatan penelitian yang digunakan adalah cross sectional. Penelitian cross sectional (potong lintang) adalah suatu penelitian dengan cara pendekatan, observasi atau pengumpulan data pada satu waktu (poin time approach). Artinya setiap subjek penelitian hanya diobservasi sekali saja dan pengukuran dilakukan terhadap status karakter subjek pada saat penelitian ${ }^{6}$. Populasi pada penelitian ini penelitian ini yang dijadikan populasi adalah orang tua yang memiliki anak usia toddler. Adapun jumlahnya yaitu 41 orang. Sampel dalam penelitian ini adalah semua orang tua yang memiliki anak usia toddler sebanyak 41 orang. Teknik pengambilan sampel menggunakan total sampling.

\section{HASIL}

Tabel 1

Distribusi Frekuensi Faktor Pengetahuaan Orang Tua, Sikap, Pengawasan dan Pencegahan Cidera

\begin{tabular}{lcc}
\hline \multicolumn{1}{c}{ Pengetahuan } & Frekuensi & $\begin{array}{c}\text { Persen } \\
(\mathbf{\%})\end{array}$ \\
\hline Kurang Baik & 24 & 58.5 \\
Baik & 17 & 41.5 \\
\hline Sikap & & \\
\hline Kurang Baik & 29 & 70.7 \\
Baik & 12 & 29.3 \\
\hline Pengawasan & & \\
\hline Kurang Baik & 23 & 56.1 \\
Baik & 18 & 43.9 \\
\hline PencegahanCedera & & \\
\hline Kurang Baik & 21 & 51.2 \\
Baik & 20 & 48.8 \\
\hline
\end{tabular}

Tabel 2

Hubungan Faktor Pengetahuan Orang Tua Dengan Pencegahan Cedera Pada Anak Usia Toodler Di PAUD Tunas Bangsa

\begin{tabular}{lcccccccc}
\hline $\begin{array}{c}\text { Pencegahan } \\
\text { Cedera }\end{array}$ & & & & & & & \\
\end{tabular}


Tabel 3

Hubungan Faktor Sikap Orang Tua Dengan Pencegahan Cedera Pada Anak Usia Toodler Di PAUD Tunas Bangsa

\begin{tabular}{lcccccccc}
\hline $\begin{array}{l}\text { Pencegahan } \\
\text { Sikap }\end{array}$ & $\begin{array}{c}\text { Kurang } \\
\text { Baik }\end{array}$ & \multicolumn{2}{c}{ Baik } & \multicolumn{2}{c}{ Total } & \multirow{2}{*}{ P value } & OR (95\% CI) \\
\cline { 2 - 6 } & $\mathbf{F}$ & $\mathbf{\%}$ & $\mathbf{F}$ & $\mathbf{\%}$ & $\mathbf{F}$ & $\mathbf{\%}$ & & \\
\hline Kurang Baik & 17 & 58.6 & 12 & 41.4 & 29 & 100 & & \\
Baik & 4 & 33.3 & 8 & 66.7 & 12 & 100 & 0.258 & $2.833(11.599-0.692)$ \\
$\quad$ Jumlah & 21 & 51.2 & 20 & 48.8 & 41 & 100 & & \\
\hline
\end{tabular}

Tabel 4

Hubungan Faktor Pengawasan Orang Tua Dengan Pencegahan Cedera Pada Anak Usia Toodler Di PAUD Tunas Bangsa

\begin{tabular}{|c|c|c|c|c|c|c|c|c|}
\hline \multirow{2}{*}{$\begin{array}{c}\text { Pencegahan } \\
\text { Cedera }\end{array}$} & \multicolumn{2}{|c|}{$\begin{array}{c}\text { Kurang } \\
\text { Baik }\end{array}$} & \multicolumn{2}{|c|}{ Baik } & \multicolumn{2}{|c|}{ Total } & \multirow{2}{*}{$\begin{array}{c}\mathbf{P} \\
\text { value }\end{array}$} & \multirow{2}{*}{ OR (95\% CI) } \\
\hline & $\mathbf{F}$ & $\%$ & $\mathbf{F}$ & $\%$ & $\mathbf{F}$ & $\%$ & & \\
\hline Kurang Baik & $\begin{array}{l}1 \\
5\end{array}$ & 65.2 & 8 & 34.8 & 23 & 100 & & \\
\hline Baik & 6 & 33.3 & 12 & 66.7 & 18 & 100 & 0.087 & $3.750(13.795-1.019)$ \\
\hline Jumlah & $\begin{array}{l}2 \\
1\end{array}$ & 51.2 & 20 & 48.8 & 41 & 100 & & \\
\hline
\end{tabular}

Dari tabel 1 dapat dijelaskan bahwa sebagian besar responden memiliki tingkat pengetahuan dengan kategori kurang baik yaitu sebesar 24 (58,5\%), memiliki sikap dengan kategori kurang baik yaitu sebesar 29 (70,7\%), memiliki pencegahan cedera dengan kategori kurang baik yaitu sebesar 21 (51,2\%), dan memiliki pengawasan dengan kategori kurang baik yaitu sebesar 23 (56,1\%).

Tabel 2 mengenai faktor yang paling berhubungan dengan pencegahan cedera pada anak usia toodler. Diperoleh hasil bahwa faktor yang paling berpengaruh terhadap pencegahan cedera adalah faktor pengetahuan dengan Pvalue $<0,001(<0.05)$ dengan odds Ratio sebesar 0.011 (0.001-0.130).

Tabel 3 dapat disimpulkan bahwa tidak ada hubungan antara faktor sikap orang tua dengan pencegahan cedera pada anak usia toodler di PAUD Tunas Bangsa tahun 2018 didapatkan Pvalue 0,258 (<0.05) dengan odds Ratio sebesar 2.833 (11.599-0.692).

Tabel 4 Dapat disimpulkan bahwa ada hubungan antara faktor pengawasan orang tua dengan pencegahan cedera pada anak usia toodler di PAUD Tunas Bangsa tahun 2018, didapatkan Pvalue 0,087 $(<0.05)$ dengan odds Ratio sebesar 3.750 (13.795-1.019).

\section{PEMBAHASAN}

Pengetahuan, Sikap, Pengawasan dan Pencegahan Cidera

Hasil penelitian didapatkan sebagaian besar $(58,5 \%)$ pengetahuan orang tua tentang pencegahan cedera adalah kurang baik. Sejalan dengan hasil penelitian yang berjudul hubungan 
pengetahuan dan sikap ibu dalam mencegah cedera pada anak pra sekolah di serangan Yogyakarta. Hasil penelitian didapatkan sebagian besar responden $(59,1 \%)$ memiliki pengetahuan kurang baik ${ }^{7}$.

Sejalan dengan teori yang menyatakan pengetahuan merupakan hasil dari tahu, dan terjadi setelah orang melakukan penginderaan terhadap suatu objek tertentu. Penginderaan terjadi melalui penciuman manusia, yakni indra penglihatan dan pendengaran manusia, yakni indra penglihatan, pedengaran, penciuman, rasa dan raba. Sebagain besar pengetahuan manusia diperoleh melalui mata dan telinga. Kemudian perilaku seseorang tentang kesehatan didorong oleh 3 faktor yaitu : faktor predesposisi (predisposissing factor) adalah suatu keadaan yang dapat mempermudah dalam mempengarui individu untuk berperilaku yang terwujud dalam pengetahuan, sikap, kepercayaan, nilai- nilai, faktor demografi seperti status ekonomi, umur, jenis kelamin, tinggkat pendidikan, pengalaman, faktor pendukung (enabling factor) berkaitan dengan lingkungan fisik, tersedianya sarana dan fasilitas kesehatan misalnya puskesmas, obatobatan dan lain-lain.

Faktor pendorong (reinforcing factor) terwujud dalam sikap dan perilaku petugas kesehatan, atau petugas yang lain, yang merupakan kelompok referensi dari perilaku masyarakat seperti tokoh agama, tokoh masyarakat dan lain-lain ${ }^{5}$.

Menurut asumsi peneliti banyaknya responden yang mimiliki pengetahuan kurang baik karena kurangnya sumber informasi tentang pencegahan cedera. Informasi yang didapatkan masih sedikit sehingga orang tua tidak terlalu menghiraukan cedera pada anak. Mereka mengangap apabila anak cedera dapat dilarikan ke fasilitas kesehatan, ditunjang juga dengan belum adanya pengalaman orang tua tentang pencegahan cedera kepada anaknya.

Berdasarkan hasil pengolahan data didapatkan sebagaian besar (70,7\%) sikap orang tua tentang pencegahan cedera adalah kurang baik.

Sejalan dengan hasil penelitian yang berjudul hubungan pengetahuan dan sikap ibu dalam mencegah cedera pada anak pra sekolah di serangan Yogyakarta. Hasil penelitian didapatkan sebagian besar $(62,6 \%)$ responden memiliki sikap yang kurang baik ${ }^{7}$.

Teori yang menyatakan sikap kaitannya dengan efek dan perannya dalam pembentukan karakter dan sistem hubungan antar kelompok, serta pilihan-pilihan yang ditentukan berdasarkan lingkungan dan pengaruhnya terhadap perubahan $^{8}$. Faktor-faktor yang mempengaruhi sikap terhadap objek sikap, antara lain: pengalaman pribadi, sikap akan lebih mudah terbentuk apabila pengalaman tersebut terjadi dalam situasi yang melibatkan faktor emosional. Pengaruh orang lain yang dianggap penting, pengaruh kebudayaan, media massa, lembaga pendidikan dan lembaga agama dan faktor emosional $^{8}$.

Menurut asumsi peneliti sikap orang tua yang kurang baik karena mereka menganggap anaknya tidak akan cedera. Lingkungan tempat bermain anak dianggap aman sehingga orang tua tidak perlu tanggap terhadap pemicu cedera pada anak. Sedangkan sikap yang baik karena orang tua merasa anak perlu di perhatikan walaupun tidak secara khusus karena pemicu cedera dapat terjadi dari segala arah.

Berdasarkan hasil pengolahan data didapatkan sebagaian besar $(56,1 \%)$ pengawasan orang tua tentang pencegahan cedera adalah kurang baik. Sejalan dengan penelitian yang berjudul hubungan pengetahuan dan sikap ibu dalam mencegah cedera pada anak usia toddler di Sleman Yogyakarta. Berdasarkan hasil uji statistik didapatkan pengawasan orang tua yang dilakukan sebagian besar $(51,7 \%)$ adalah kurang baik $^{9}$.

Sejalan dengan teori yang menyatakan pengawasan orang tua adalah suatu keberhasilan anaknya antara lain ditujukan dalam bentuk 
perhatian terhadap kegitan pelajaran disekolah dan menekankan arti penting pencapaian pretasi oleh sang anak, tapi disamping itu orang tua perlu menghadirkan pribadi sukses yang dapat dijadikan teladan bagi anak ${ }^{10}$.

Menurut asumsi penelitian pengawasan orang tua yang kurang baik karena orang tua sudah mempercayai anaknya, sehingga mereka tidak melakukan pengawasan kepada anaknya. Orang tua mengangap anak sudah mengerti apa saja yang tidak boleh di mainkan dan dapat menjadi pemicu cedera.

Berdasarkan hasil pengolahan data didapatkan sebagaian besar $(51,2 \%)$ pencegahan cedera orang tua kepada anak usia toddler adalah kurang baik. Sejalan dengan penelitian yang berjudul hubungan pengetahuan dan sikap ibu dalam mencegah cedera pada anak pra sekolah di serangan yogyakarta. Berdasarkan hasil uji statistic didapatkan mencegah cedera pada anak pra sekolah sebagian besar $(61,9 \%)$ kurang baik ${ }^{7}$. Cedera adalah dampak dari suatu agen eksternal yang menimbulkan kerusakan, baik fisik maupun mental. Peran orang tua terhadap anak usia toddler yaitu memahami tumbuh kembang anak, memenuhi kebutuhan gizi, memberikan kebebasan agar mereka dapat melakukan berbagai hal yang tidak membahayakan, mengnyimpan benda-benda yang dapat membahayakan anak, mengawasi setiap yang dilakukan anak ${ }^{11}$. Untuk mengurangi cedera pada anak orang tua harus memiliki pengetahuan tentang pencegahan cedera, sikap tanggap terhadap hal yang dilakukan anak dan pengawasan gerak- gerik anak

\section{Faktor Pengetahuan Orang Tua Dengan dan Pencegahan Cedera}

Berdasarkan hasil pengolahan data dapat disimpulkan bahwa ada hubungan antara faktor pengetahuan orang tua dengan pencegahan cedera pada anak usia toodlerdi PAUD Tunas Bangsa didapatkan Pvalue $<0,001(<0.05)$ dengan odds Ratio sebesar 80.000(788.252 - 8,119) dimana orang tua yang memiliki pengetahuan kurang baik akan berisiko sebesar $80.000 \mathrm{kali}$ untuk melakukan pencegahan cedera kurang baik.

Sejalan dengan penelitian berjudul penelitian hubungan antara pengetahuan dan sikap orang tua tentang bahaya cedera dan cara pencegahannya dengan praktik pencegahan cedera pada anak usia Toddler di Kelurahan Blumbang Kecamatan Tawangmangu Kabupaten Karanganyar ${ }^{9}$. Hasil analisa bivariat didapatkan hubungan antara pengetahuan dengan praktik pencegahan cedera dengan $\mathrm{OR}=4.455$ dan $\mathrm{CI}$ 95\% (1.284-15.449).

Sejalan dengan teori yang menyatakan pengetahuan merupakan hasil dari tahu, dan terjadi setelah orang melakukan penginderaan terhadap suatu objek tertentu. Kemudian perilaku seseorang tentang kesehatan didorong oleh 3 faktor yaitu : faktor predesposisi (predisposissing factor), faktor pendukung (enabling factor), dan faktor pendorong (reinforcing factor).Untuk mengurangi cedera pada anak orang tua harus memiliki pengetahuan tentang pencegahan cedera, sikap tanggap terhadap hal yang dilakukan anak dan pengawasan gerak-gerik anak. Pemahaman orang tua terhadap perkembangan anak sangat penting untuk menghindari cedera pada anak ${ }^{13}$.

Menurut asumsi peneliti pada hasil penelitian didapatkan banyak pengetahuan orang tua yang kurang baik namun dengan pencegahan cedera baik. Ini dapat dikarenakan pengetahuan yang orang tua dapatkan atau sumber informasi yang didapatkan tentang teori pencegahan cedera masih sedikit sehingga dapat mempengaruhi hasil kuesioner penelitian. Sedangkan pencegahan yang baik karena bisa didapatkan dari pengalaman sebelumnya tentang pencegahan cedera dan juga dari sosial budaya yang di praktikan kepada anak. 


\section{Faktor Sikap Orang Tua dan Pencegahan Cedera}

Berdasarkan hasil pengolahan data dapat disimpulkan bahwa tidak ada hubungan antara faktor sikaporang tua dengan pencegahan cedera pada anak usia toodlerdi PAUD Tunas Bangsa didapatkan Pvalue 0,258 (<0.05) dengan odds Ratio sebesar 2.833 (11.599- 0.692) dimana orang tua yang memiliki sikap kurang baik akan berisiko sebesar 2.833 kali untuk melakukan pencegahan cedera kurang baik.

Hasil penelitian ini sejalan dengan penelitian berjudul penelitian hubungan antara pengetahuan dan sikap orang tua tentang bahaya cedera dan cara pencegahannya dengan praktik pencegahan cedera pada anak usia Toddler di Kelurahan Blumbang Kecamatan Tawangmangu Kabupaten Karanganyar ${ }^{12}$. Hasil analisa bivariat didapatkan tidak terdapat hubungan antara sikap dengan praktik pencegahan cedera dengan $\mathrm{OR}=$ 9.962 dan CI 95\% (2.774-35.768).

Sejalan dengan teori sikapkaitannya dengan efek dan perannya dalam pembentukan karakter dan sistem hubungan antar kelompok, serta pilihan-pilihan yang ditentukan berdasarkan lingkungan dan pengaruhnya terhadap perubahan $^{8}$. Faktor-faktor yang mempengaruhi sikap terhadap objek sikap antara lain:Pengalaman pribadi (untuk dapat menjadi dasar pembentukan sikap, pengalaman pribadi haruslah meninggalkan kesan yang kuat. karena itu, sikap akan lebih mudah terbentuk apabila pengalaman tersebut terjadi dalam situasi yang melibatkan faktor emosional), pengaruh orang lain yang dianggap penting, pengaruh kebudayaan, media massa (dalam pemberitaan surat kabar maupun radio atau media komunikasi lainnya, berita yang seharusnya faktual disampaikan secara objektif cenderung dipengaruhi oleh sikap penulisnya, akibatnya berpengaruh terhadap sikap konsumennya), lembaga pendidikan dan lembaga agama (konsep moral dan ajaran dari lembaga pembaga pendidikan dan lembaga agama sangat menentukan sistem kepercayaan, tidaklah mengherankan jika kalau pada gilirannya konsep tersebut mempengaruhi sikap) dan faktor emosional).

Menurut asumsi peneliti pada hasil penelitian didapatkan sikap orang tua sebagian besar kurang baik namun pencegahan cedera yang dilakukan baik. Ini dikarenakan sikap orang tua yang kurang baik karena mereka menggangap anaknya tidak akan cedera. Lingkungan tempat bermain anak dianggab aman sehingga orang tua tidak perlu tanggap terhadap pemicu cedera pada anak. Pencegahan cedera yang baik karena orang tua walaupun merasa anaknya aman mereka tetap melakukan penyimpanan terhadap benda-benda yang dapat menjadi pemicu cedera.

\section{Faktor Pengawasan Orang Tua dan Pencegahan Cedera}

Dapat disimpulkan bahwa ada hubungan antara faktor pengawasanorang tua dengan pencegahan cedera pada anak usia toodler di PAUD Tunas Bangsa,didapatkan Pvalue 0,087 $(<0.05)$ dengan odds Ratio sebesar 3.750 (13.795-1.019) dimana orang tua yang memiliki pengawasan kurang baik akan berisiko sebesar 3.750 kali untuk melakukan pencegahan cedera kurang baik.

Sejalan dengan teori yang berjudul penelitian hubungan pengetahuan dan sikap ibu dalam mencegah cedera pada anak usia toddler di Sleman Yogyakarta ${ }^{9}$. Berdasarkan hasil uji statistic didapatkan pengawasan terdapat hubungan dengan pencegahan cedera dengan nilai p-value 0.001.Sejalan dengan teori yang menyatakan bahwa pengawasan orang tua adalah suatu keberhasilan anaknya antara lain ditujukan dalam bentuk perhatian terhadap kegitan pelajaran disekolah dan menekankan arti penting pencapaian prestasi oleh sang anak, tapi disamping itu orang tua perlu menghadirkan pribadi sukses yang dapat dijadikan teladan bagi 
anak. Pengawasan orang tua dalam pendidikan anak-anaknya dirumah berhubugan dengan Potensi anak, perilaku anak,budaya. Anak merupakan tumpuan dan harapan di masa depan, maka orang tua senantiasa memperhatikan pertumbuhan dan perkembangan anak-anaknya serta mengubah prilaku anak-anaknya. Semua orang tua berperan aktif dalam pendidikan anak dan ingin melihat anaknya berhasil di sekolah, oleh karena itu, keluarga mempunyai tugas fundamental dalam mempersiapkan anak bagi peranannya dimasa depan ${ }^{14}$.

Menurut asumsi peneliti berdasarkan hasil penelitian didapatkan pengawasan orang tua kurang baik namun pencegahan cedera yang dilakukan baik. Pencegahan cedera kurang baik karena orang tua menganggab anaknya dapat menjauhkan diri dari benda-benda yang dapat menjadi pemicu cedera sehingga orang tua tidak melakukan pencegahan secara maksimal kepada anaknya.

\section{SIMPULAN}

Hasil penelitian didaptkan kesimpulan ada hubungan antara faktor pengetahuan orang tua dengan pencegahan cedera didapatkan Pvalue $<0,001 \quad(<0.05) \quad$ dengan odds Ratio sebesar 80.000 (788.252 - 8,119). Tidak ada hubungan antara faktor sikap orang tua dengan pencegahan cedera didapatkan Pvalue 0,258 $(<0.05)$ dengan odds Ratio sebesar 2.833 (11.599- 0.692). Ada hubungan antara faktor pengawasan orang tua dengan pencegahan cedera didapatkan Pvalue $0,087(<0.05)$ dengan odds Ratio sebesar 3.750 (13.795-1.019). Dan faktor yang paling berpengaruh terhadap pencegahan cedera adalah faktor pengetahuan dengan Pvalue $<0,001$ $(<0.05)$ dengan odds Ratio sebesar 0.011 (0.001$0.130)$.

\section{SARAN}

Sikap orang tua lebih tanggap melakukan pertolongan pada anak yang cedera kemudian lebih berhati-hati dalam mendampingi tumbuh kembang anak karena rasa penasaran anak yang tinggi dapat mengakibatkan adanya cedera pada anak. Dapat menjadi masukan untuk bekerja sama lintas sektoral seperti puskesmas agar para orang tua diberikan penyuluhan tentang penanganan cedera pada anak dan dapat menjadi masukan agar para tenaga kesehatan melakukan penyuluhan tentang penanganan cedera pada anak kepada orang tua sehingga dapat mengurangi angka kesakitan pada anak.

\section{DAFTAR PUSTAKA}

1. WHO (2012). Angka Kejadian cedera pada anak di Dunia. Diperoleh tanggal 12 Oktober 2017

2. Riset Kesehatan Dasar. (2013). Angka kejadian Cedera pada anak. Diperoleh pada tanggal 10 Oktober 2017

3. Profil Kesehatan, (2014). Angka kejadian cedera di Lampung. Lampung. Diperoleh pada tanggak 15 Oktober 2017

4. Kuschithawati, Rahadyan \& Nawi. (2007). Faktor Risiko Terjadinya Cedera Pada Anak Usia Sekolah Dasar. Jurnal Keperawatan

5. Notoatmodjo. (2012). Metodologi Penelitian Kesehatan (Edisi Revisi), Rineka Cipta, Jakarta.

6. Arikunto. (2010), Prosedur Penelitian Suatu Pendekatan Praktek, Rineka Cipta ;Jakarta

7. Ayu W. (2014). Hubungan pengetahuan dan sikap ibu dalam mencegah cedera pada anak pra sekolah di serangan yogyakarta. Jurnal Keperawatan

8. Saifudin A. (2000). Prosedur Penliaian teori sikap. Rineka Cipta ;Jakarta

9. Ratna U. (2012). Hubungan pengetahuan dan sikap ibu dalam mencegah cedera pada anak usia toddler di Sleman Yogyakarta. Jurnal Keperawatan

10. Leving. (2002). Gaya pengawasan orang tua. Jakarta: Cendikia Press 
11. Perry \& Potter. (2010). Keperawatan Fundamental. EGC; Jakarta

12. Ratna .D \& Indarwati. (2011). Hubungan antara pengetahuan dan sikap orang tua tentang bahaya cedera dan cara pencegahannya dengan praktik pencegahan cedera pada anak usia Toddler di Kelurahan Blumbang Kecamatan Tawangmangu Kabupaten Karanganyar. Jurnal Keperawatan 13. Kusbiantoro. D. (2014). Praktik Pencegahan Cedera Pada Anak Usia Toddler Ditinjau
Dari Pengetahuan Dan Sikap Orang Tua Tentang Bahaya Cedera Di Desa Kembangbahu Kecamatan Kembangbahu Kabupaten Lamongan. Jurnal Keperawatan 14. Hastuti. D. (2017). Hubungan Pengetahuan Tentang Antisipasi Cedera Dengan Praktik Pencegahan Cedera Pada Anak Usia Toddler Di RW 01 Kelurahan Manggahang Wilayah Puskesmas Jelekong Kabupaten Bandung. Jurnal Keperawatan. 